\title{
molecules
}

ISSN 1420-3049

(C) 2007 by MDPI

www.mdpi.org/molecules

Full Paper

\section{Relative Stereochemistry of a Diterpene from Salvia cinnabarina}

\author{
Angela Bisio ${ }^{1}$, Bruno Pagano ${ }^{2}$, Alessia Romussi ${ }^{3}$, Olga Bruno ${ }^{3}$, Nunziatina De Tommasi ${ }^{2}$, \\ Giovanni Romussi ${ }^{1}$ and Carlo Andrea Mattia ${ }^{2, *}$ \\ ${ }^{1}$ Dipartimento di Chimica e Tecnologie Farmaceutiche e Alimentari, Università di Genova, Via \\ Brigata Salerno, Genova, Italy \\ 2 Dipartimento di Scienze Farmaceutiche, Università di Salerno, Via Ponte Don Melillo, 84084 \\ Fisciano, Salerno, Italy \\ ${ }^{3}$ Dipartimento di Scienze Farmaceutiche, Università di Genova, Viale Benedetto XV, Genova, Italy \\ * Author to whom correspondence should be addressed. E-mail: mattia@unisa.it \\ Tel.: +39089 969759, Fax: +39089969602
}

Received: 27 September 2007; in revised form: 5 October 2007 / Accepted: 5 October 2007 / Published: 9 October 2007

\begin{abstract}
The relative stereochemistry of 3,4-secoisopimara-4(18),7,15-triene-3-oic acid, a diterpenoid with antispasmodic, hypotensive and antibacterial activities isolated from Salvia cinnabarina, was determined by an X-ray diffraction analysis of a single crystal of a suitable crystalline derivative.
\end{abstract}

Keywords: Salvia cinnabarina, Lamiaceae, secoisopimarane-diterpene, relative stereochemistry, X-ray structure.

\section{Introduction}

The genus Salvia (family Lamiaceae) includes over 900 species growing in the temperate and tropical zones of the world; and various taxa of this genus are commonly used in traditional medicine [1]. Interesting bioactive compounds isolated from Salvia species are flavonoids, essential oils, diterpenes, and triterpenes with antifeedant, antibacterial, antifungal [2, 3], hallucinogenic [3] and antioxidant activities [4]. 
In previous papers we have described the antispasmodic, hypotensive and antibacterial activities of a new secoisopimarane diterpenoid isolated from Salvia cinnabarina M. Martens and Galeotti, whose relative stereochemistry could be only partially determined on the basis of NMR spectroscopic techniques [5-9]. We now report the complete relative stereochemistry of this compound, determined by an X-ray diffraction analysis of a single crystal of a suitable crystalline derivative.

\section{Results and Discussion}

In a previous paper, and on the basis of NMR spectroscopic techniques, we were able to report only the relative configuration at C-9 and C-13 of 3,4-secoisopimara-4(18),7,15-triene-3-oic acid (1), as the compound did not give crystals suitable for X-ray diffraction analysis. In order to confirm these partial results and to obtain the complete relative stereochemistry of $\mathbf{1}$ we have now prepared derivatives of the carboxylate group since this group was the most suitable for synthesis of derivatives without changes in the configuration of the rings (Scheme 1).

Scheme 1. Chemical structures of compounds 1 - 4 .
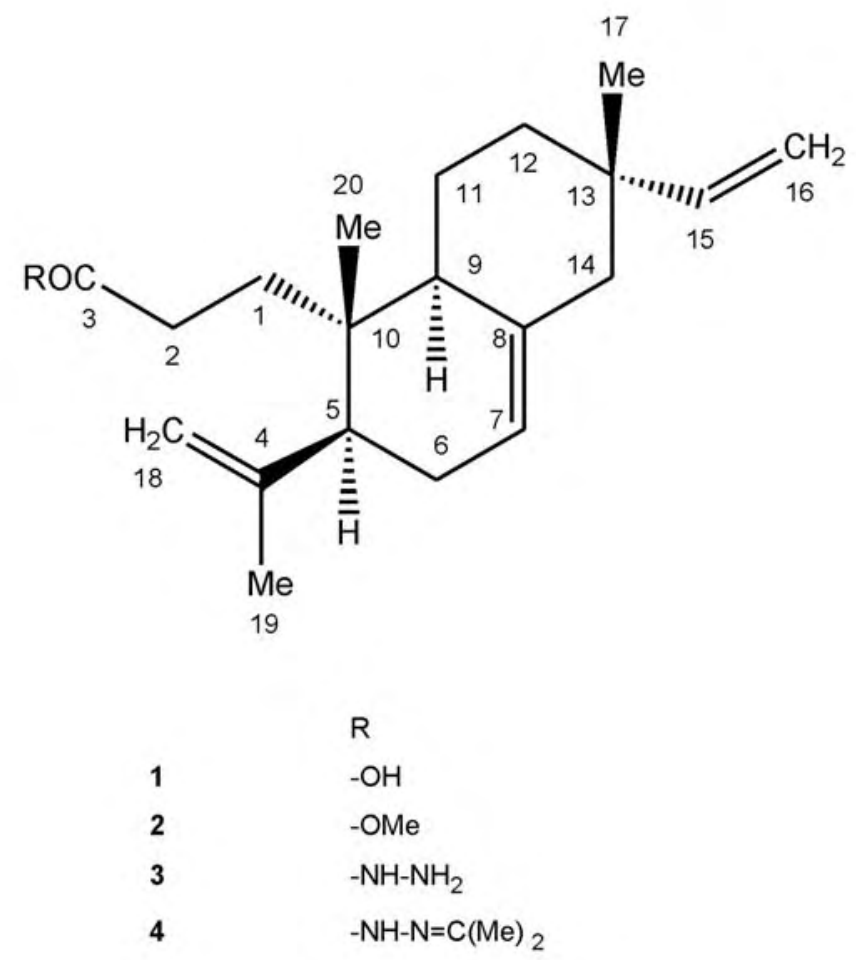

We prepared the methyl ester $\mathbf{2}$ (an oil) from the sodium salt of $\mathbf{1}$ and methyl iodide and then the hydrazide $\mathbf{3}$ by treatment of $\mathbf{2}$ with hydrazine hydrate. Since compound $\mathbf{3}$ did not give suitable crystals either, we prepared the acetone derivative 4, which finally provided crystals suitable for X-ray diffraction analysis. Since compounds 1, 2, 3 and 4 showed in the ${ }^{13} \mathrm{C}-\mathrm{NMR}$ practically identical signals for the 19 carbons of the diterpenoid moiety and only the substituted C-3 showed different $\delta$ values (Table 1), it may be inferred that the same relative stereochemistry is maintained in all compounds. 
Table 1. ${ }^{13} \mathrm{C}-\mathrm{NMR}$ spectral data $\left(\delta\right.$ values, $\left.\mathrm{CDCl}_{3}\right)$.

\begin{tabular}{|c|c|c|c|c|}
\hline $\mathrm{C}$ & $1^{\mathrm{a}}$ & 2 & 3 & 4 \\
\hline 1 & 32.0 & 32.2 & 33.0 & 31.9 \\
\hline 2 & 29.0 & 28.8 & 29.1 & 29.4 \\
\hline 3 & 181.0 & 174.7 & 174.6 & $176.3^{\mathrm{b}}$ \\
\hline 4 & 147.3 & 147.3 & 147.8 & 147.5 \\
\hline 5 & 49.5 & 49.4 & 49.8 & 49.0 \\
\hline 6 & 29.3 & 29.3 & 29.1 & 29.4 \\
\hline 7 & 121.4 & 121.4 & 121.3 & 121.3 \\
\hline 8 & 136.0 & 136.0 & 136.0 & 136.2 \\
\hline 9 & 44.4 & 44.2 & 44.2 & 43.9 \\
\hline 10 & 37.6 & 37.6 & 37.5 & 37.8 \\
\hline 11 & 21.0 & 20.9 & 20.8 & 20.8 \\
\hline 12 & 36.3 & 36.3 & 36.2 & 36.3 \\
\hline 13 & 37.0 & 37.0 & 36.9 & 37.0 \\
\hline 14 & 46.4 & 46.4 & 46.4 & 46.4 \\
\hline 15 & 150.1 & 150.1 & 150.0 & 150.3 \\
\hline 16 & 109.4 & 109.4 & 109.4 & 109.3 \\
\hline 17 & 21.5 & 21.5 & 21.5 & 21.5 \\
\hline 18 & 114.0 & 113.9 & 113.9 & 113.7 \\
\hline 19 & 23.7 & 23.7 & 23.3 & 23.9 \\
\hline 20 & 16.7 & 16.7 & 16.8 & 17.0 \\
\hline COOMe & - & 51.5 & - & - \\
\hline $\mathrm{C}=\mathrm{N}$ & - & - & - & $148.6^{c}$ \\
\hline \multicolumn{5}{|l|}{ Acetone } \\
\hline moiety Me & - & - & - & 25.4 and 27 \\
\hline
\end{tabular}

\footnotetext{
${ }^{a}$ Reference [5]; ${ }^{b}$ this $\mathrm{C}$ showed an HMBC correlation with the NH proton at $\delta$ 8.53;

${ }^{\mathrm{c}}$ this $\mathrm{C}$ showed $\mathrm{HMBC}$ correlations with the $\mathrm{NH}$ proton and the Me protons of the acetone moiety at $\delta 1.95$ and 1.79 .
}

In the crystal of $\mathbf{4}$ the asymmetric unit is formed by two independent molecules. A perspective view of one molecule is shown in Figure 1, together with the atomic labelling scheme. The two molecules are related by a non-crystallographic pseudo-twofold axis and are stabilized by means of two intermolecular hydrogen bonds: $\mathrm{N} 1 \cdots \mathrm{O} 1^{\prime}=2.894$ (3) $\AA$, and $\mathrm{N} 1^{\prime} \cdots \mathrm{O} 1=2.953$ (4) $\AA$ (Figure 2). They present geometric and conformational similarities, the only difference being observed for the $\mathrm{C} 16$ atom of the ethylenic group, which is rotated about $70^{\circ}$ around the C13-C15 bond in one structure compared with the other. Upon best-fit superposition, the r.m.s. deviation of corresponding atoms, excluding the side substituents, is only $0.044 \AA$. Bond lengths and angles are within the expected 
ranges and generally agree well with the values reported in the literature for correlated molecules [1619].

Figure 1. The molecular structure of $\mathbf{4}$, with the atomic labelling for non-H atoms.

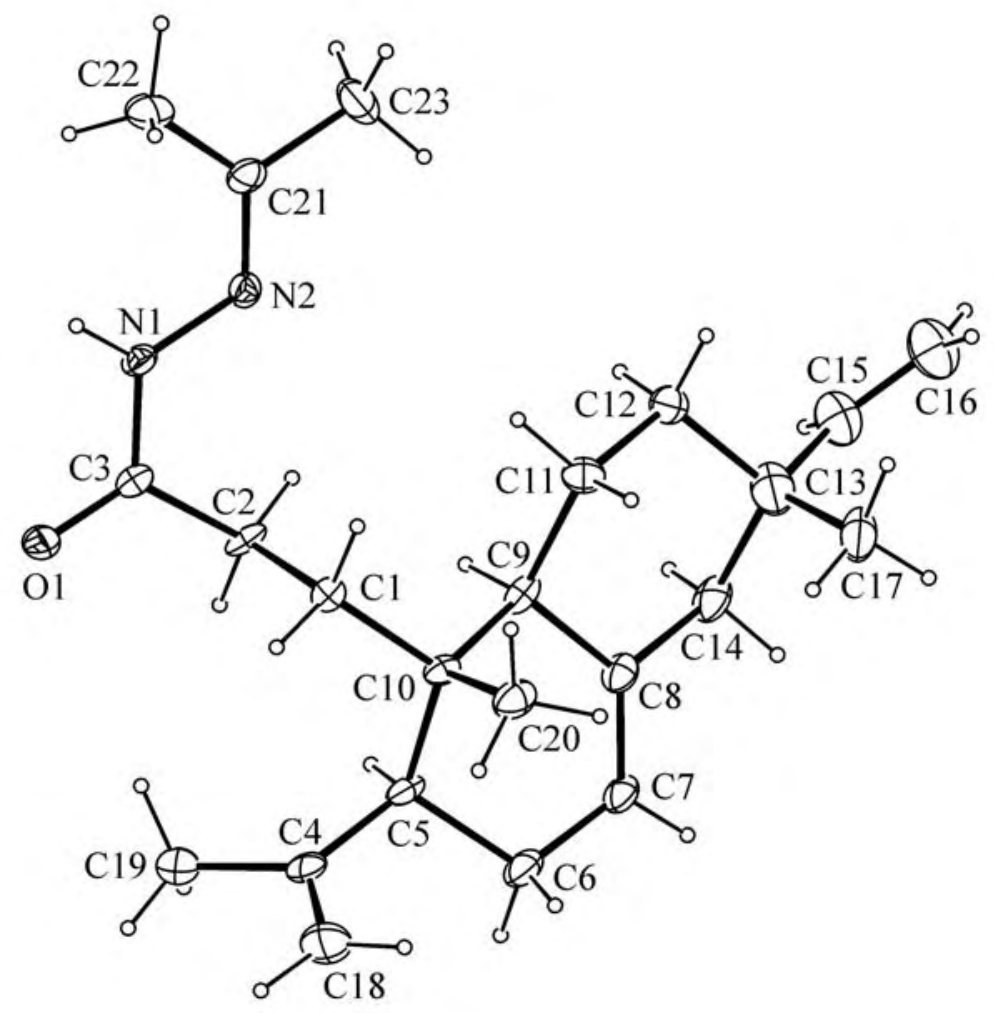

The cyclohexene ring adopts a half-chair conformation, with atomic displacements of 0.415 (4) (for C5) and 0.390 (3) Å (for C10) for one molecule, and 0.456 (4) (for C5') and 0.358 (3) Å (for C10') for the other. The puckering parameters [20] of the cyclohexene are: $Q=0.526$ (3) $\AA, \theta=52.7(4)^{\circ}$ and $\varphi_{2}$ $=30.8(5)^{\circ}$ for the first molecule, and $Q=0.533$ (4) $\AA, \theta=53.6(4)^{\circ}$ and $\varphi_{2}=33.5(5)^{\circ}$ for the second one. On the other hand, the cyclohexane ring approximates to an ideal chair, with puckering parameters $Q=0.524$ (4) $\AA, \theta=9.1(4)^{\circ}, \varphi_{2}=39(3)^{\circ}$ and $Q=0.534$ (4) $\AA, \theta=11.3(5)^{\circ}, \varphi_{2}=36(2)^{\circ}$ for the first and second molecule, respectively. The atomic displacements are 0.546 (4) (for C8) and 0.663 (4) $\AA$ (for C12) for the first molecule, and 0.532 (4) (for C8') and 0.680 (4) $\AA$ (for C12') for the second one.

In the absence of atoms with strong anomalous scattering, the absolute configuration was not determined and the configuration shown was chosen arbitrarily. On this basis, the relative configurations at the chiral centers are fixed as C5S*, C9S*, C10S* and C13S*.

Thus, taking into account the X-ray structure of derivative $\mathbf{4}$, in the original natural compound $\mathbf{1} \mathrm{H}$ 5 and $\mathrm{H}-9$ are axial and on the opposite side of the 20 axial methyl group; moreover, the vinyl group at C-13 is equatorial and the C-17 axial methyl group is on the same side of the C-20 axial methyl group. These results are in agreement with the partial stereochemistry previously determined with NMR spectroscopic techniques and with the signal of the $\mathrm{H}-5$ at $\delta 2.18$ in the ${ }^{1} \mathrm{H}-\mathrm{NMR}$ spectrum of $\mathbf{1}$, which showed one axial/axial $\left(\mathrm{J}_{5 \mathrm{ax} / 6 \mathrm{ax}}=12.0 \mathrm{~Hz}\right)$ and one axial/equatorial $\left(\mathrm{J}_{5 \mathrm{ax} / 6 \mathrm{eq}}=3.0 \mathrm{~Hz}\right)$ coupling, typical of an axial configuration [5]. 
Figure 2. A perspective view of the two independent molecules of $\mathbf{4}$. Dotted lines indicate the two intermolecular hydrogen bonds.

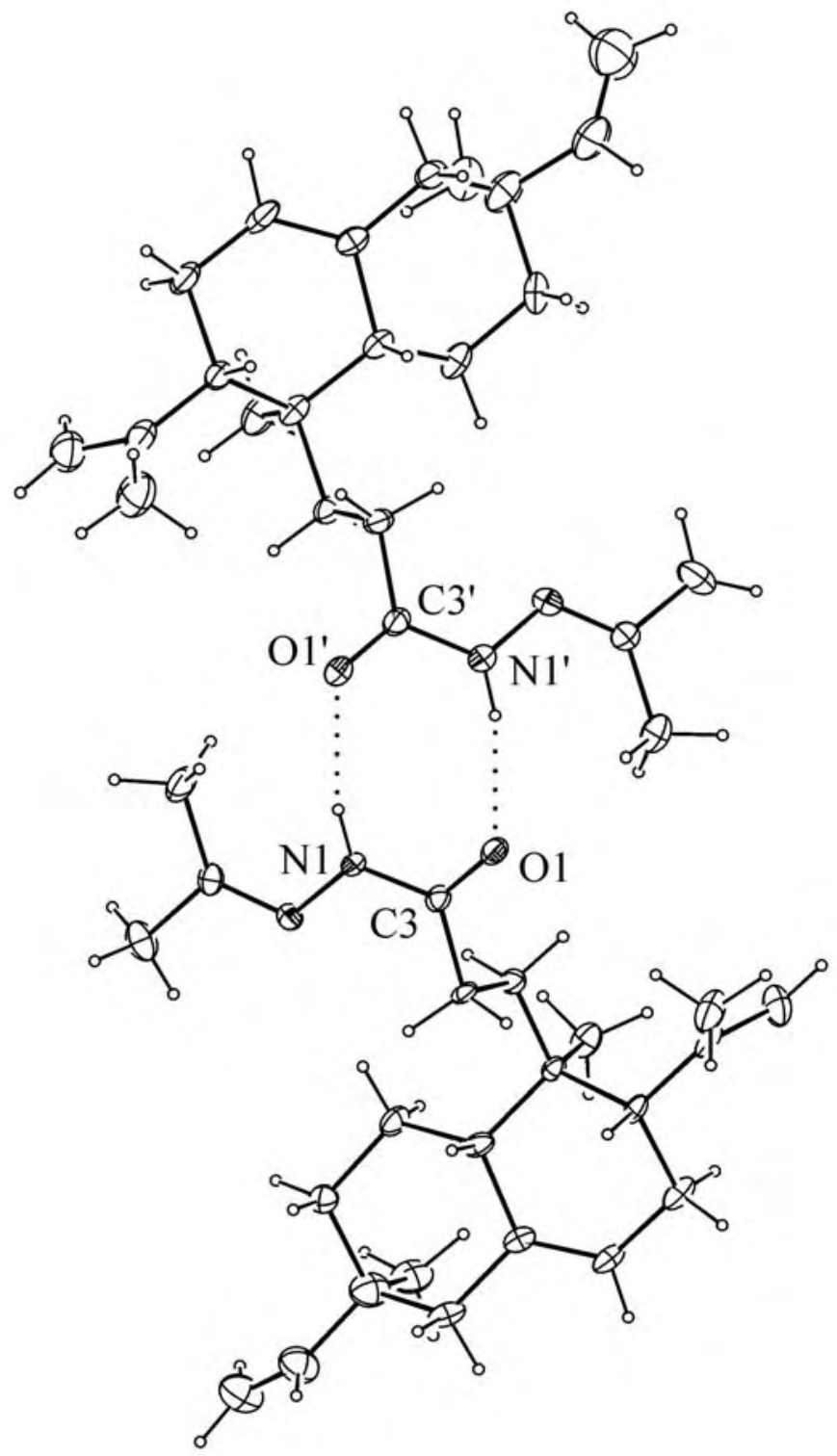

\section{Experimental}

\section{General}

Silica gel 60 (Merck 230-400 mesh) was used for column chromatography; aluminium sheets of silica gel $60 \mathrm{~F}_{254}$ (Merck $0.2 \mathrm{~mm}$ thick) with $\mathrm{CHCl}_{3} / \mathrm{MeOH}$ (12:05) as eluent were used and the spots were detected by spraying $5 \% \mathrm{H}_{2} \mathrm{SO}_{4}$, followed by heating. IR spectra were recorded on a PerkinElmer 1310 spectrophotometer. NMR spectra were recorded in $\mathrm{CDCl}_{3}$ on a BRUKER DRX 600 spectrometer (operating at $600 \mathrm{MHz}$ for ${ }^{1} \mathrm{H}$ and $150 \mathrm{MHz}$ for ${ }^{13} \mathrm{C}$ ) using TMS as internal standard. The optical rotation was recorded on a Perkin-Elmer 241MC polarimeter. Melting points are uncorrected and were measured on a Tottoli melting point apparatus (Büchi). 


\section{Extraction}

Extraction of 3,4-secoisopimara-4(18),7,15-triene-3-oic acid (1) from leaf surface constituents of fresh aerial parts of Salvia cinnabarina was performed as previously described [5]. The sodium salt was prepared by reaction with an equivalent of $\mathrm{NaOH}$ in $\mathrm{MeOH}$ solution.

\section{Synthetic procedures}

3,4-Secoisopimara-4(18),7,15-triene-3-oic acid methylester (2). $\mathrm{CH}_{3} \mathrm{I}$ (2.8 g, $20 \mathrm{mmol}$ ) was added to a solution of the sodium salt of $\mathbf{1}(0.97 \mathrm{~g}, 3 \mathrm{mmol})$ in $\mathrm{MeOH}(5 \mathrm{~mL})$ and the mixture was refluxed in an oil bath for $4 \mathrm{~h}$. Solvent and the excess of $\mathrm{CH}_{3} \mathrm{I}$ were then distilled off under vacuum and the residue extracted with $n$-hexane. The hexane solution was evaporated and the residue (oil, $0.78 \mathrm{~g}$ ) was chromatographed on a silica gel column $(1.5 \times 30 \mathrm{~cm}$, analytical TLC control) eluting with mixtures of n-hexane $-\mathrm{CHCl}_{3}[9: 10(90 \mathrm{~mL}), 8: 2(700 \mathrm{~mL})]$. Elution with 8:2 $n$-hexane $-\mathrm{CHCl}_{3}$ afforded $0.75 \mathrm{~g}$ of pure 2 (yield: $78.8 \%$ ) as an oil; $[\alpha]_{\mathrm{D}}{ }^{22}+42.2^{\circ}\left(c\right.$ 0.94, MeOH); IR (KBr) $v_{\max } 3070,1735(\mathrm{CO})$, 1628, 990, 902, $890 \mathrm{~cm}-1 ;{ }^{13} \mathrm{C}-\mathrm{NMR}$ : see Table $1{ }^{1}{ }^{\mathrm{H}-\mathrm{NMR}:} \delta 5.82(1 \mathrm{H}, \mathrm{dd}, J=11.0,17.0 \mathrm{~Hz}, \mathrm{H}-15)$; 5.38 (1H, bs, H-7); 4.94 (1H, nd, $J=17.0 \mathrm{~Hz}, \mathrm{H}-16$ trans); 4.89 (1H, nd, $J=11.0 \mathrm{~Hz}, \mathrm{H}-16$ cis); 4.88 and 4.80 (both $1 \mathrm{H}, \mathrm{ns}, \mathrm{CH}_{2}-18$ ); 3.68 (3H, s, -COOMe); 1.83 (3H, s, Me-19); 0.93 (3H, s, Me-20), 0.89 (3H, s, Me-17); Anal. C $79.62 \%$, H $10.02 \%$, calc. for $\mathrm{C}_{21} \mathrm{H}_{32} \mathrm{O}_{2}$, C $79.70 \%$, H $10.19 \%$.

3,4-Secoisopimara-4(18),7,15-triene-3-oic acid hydrazide (3). A mixture of 2 (0.95 g, 3 mmol) and hydrazine hydrate $(98 \%, 1 \mathrm{~mL})$ was heated in an oil bath at $110^{\circ} \mathrm{C}$ for $15 \mathrm{~min}$; abs. EtOH (4 mL) was then added and the solution was refluxed for $2 \mathrm{~h}$. Solvent and excess of hydrazine hydrate were distilled off under vacuum and the residue was crystallized from $n$-hexane - EtOH. Yield: $0.91 \mathrm{~g}$ of crude 3 (95.7 \%), which was purified by recrystallization from $\mathrm{MeOH}-\mathrm{H}_{2} \mathrm{O}$. Waxy crystals; m.p. 85$87^{\circ} \mathrm{C} ;[\alpha]_{\mathrm{D}}^{22}+41.2$ (c 0.90, MeOH); IR (KBr) $v_{\max } 3300(\mathrm{NH}), 3060,1640(\mathrm{CO}), 1615,988,902,885$ cm-1; ${ }^{13} \mathrm{C}-\mathrm{NMR}$ : see Table 1; ${ }^{1} \mathrm{H}-\mathrm{NMR}: \delta 7.11(1 \mathrm{H}, \mathrm{ns}, \mathrm{NH}) ; 5.78(1 \mathrm{H}, \mathrm{dd}, J=11.0,17.1 \mathrm{~Hz}, \mathrm{H}-15)$; 5.34 (1H, m, H-7); 4.96 (1H, nd, $J=17.1 \mathrm{~Hz}, \mathrm{H}-16$ trans); 4.85 (1H, nd, $J=11.0 \mathrm{~Hz}, \mathrm{H}-16$ cis); 4.84 and 4.78 (both $1 \mathrm{H}, \mathrm{ns}, \mathrm{CH}_{2}-18$ ); 3.90 (2H, brs, $\mathrm{NH}_{2}$ ); 1.79 (3H, s, Me-19); 0.96 (3H, s, Me-20), 0.85 (3H, s, Me-17); Anal. C 75.72 \%, H 10.47 \%, N 9.00 \%, calc. for $\mathrm{C}_{20} \mathrm{H}_{32} \mathrm{~N}_{2} \mathrm{O}$, C $75.90 \%$, H 10.19 \%, N $8.85 \%$.

3,4-Secoisopimara-4(18),7,15-triene-3-oil-hydrazone of acetone (4). Crude 3 (0.72 g, 2.27 mmol) was dissolved in boiling acetone $(10 \mathrm{~mL})$. The solution was concentrated, cooled to room temperature and the resulting crystalline precipitate was filtered. Yield: $0.62 \mathrm{~g}$ of crude 4 (76.4 \%), which was purified by recrystallization from acetone. M.p. $108-110^{\circ} \mathrm{C} ;[\alpha]_{\mathrm{D}}{ }^{22}+21.2^{\circ}$ (c $\left.0.90, \mathrm{MeOH}\right)$; IR $(\mathrm{KBr}) \nu_{\max } 3160(\mathrm{NH}), 3062,1650$ (CO), 990, 901, $890 \mathrm{~cm}-1 ;{ }^{13} \mathrm{C}-\mathrm{NMR}$ : see Table $1 ;{ }^{1} \mathrm{H}-\mathrm{NMR}$ : $\delta 8.53$ (1H, ns, NH); 5.77 (1H, dd, $J=11.0,17.5$ Hz, H-15); 5.33 (1H, m, H-7); 4.89 (1H, nd, $J=17.5, H-16$ trans); 4.83 (1H, nd, $J=11.0, \mathrm{H}-16$ cis); 4.83 and 4.78 (both $\left.1 \mathrm{H}, \mathrm{ns}, \mathrm{CH}_{2}-18\right) ; 1.95$ (3H, s, one Me of acetone moiety); 1.79 (6H, s, Me-19 and one Me of acetone moiety); 0.90 (3H, s, Me-20); 0.85 (3H, s, Me-17); Anal. C 77.65 \%, H 10.52 \%, N 7.87 \%, calc. for $\mathrm{C}_{23} \mathrm{H}_{36} \mathrm{~N}_{2} \mathrm{O}$, C 77.48 \%, H 10.18 \%, N 7.86 
\%. Crystals suitable for X-ray analysis were obtained by slow evaporation from an acetone solution at room temperature.

\section{$X$-ray structure determination of $\mathbf{4}$}

A selected crystal was mounted on the glass fiber and the diffraction intensity data were collected at room temperature by Nonius KappaCCD diffractometer with graphite monochromatized Mo-Ka radiation $(\lambda=0.71073 \AA)$. Accurate cell parameters were obtained by least-squares refined of the setting angles of 421 reflections at medium $\theta$ using DIRAX software [10]. Data collection were carried out with $\varphi$ and $\omega$ scans, using COLLECT software [11]. Data reduction and absorption correction were performed using SADABS [12]. Structure solution was solved using direct method (SIR97) [13] and refinement was performed using SHELXL97 software package [14]. ORTEP-3 software was employed for molecular graphics [15]. All $\mathrm{H}$ atoms were found in difference Fourier maps and were included in the final refinement assuming idealized geometry, with $\mathrm{C}-\mathrm{H}$ distances $=0.98,0.97,0.96$ and $0.93 \AA$ for tertiary $\mathrm{CH}$, secondary $\mathrm{CH}_{2}$, methyl $\mathrm{CH}_{3}$ and $\mathrm{sp}^{2} \mathrm{CH}$ atoms, respectively, and with amide $\mathrm{N}-\mathrm{H}$ distance of $0.86 \AA$. They were refining with $U_{\text {iso }}$ values equal to $1.2 U_{\text {eq }}$ parent atoms.

Crystal data: $\mathrm{C}_{23} \mathrm{H}_{36} \mathrm{~N}_{2} \mathrm{O}$ (356.54 g/mol), colorless elongated prism crystal with size $0.56 \mathrm{x} 0.18 \mathrm{x}$ $0.16 \mathrm{~mm}^{3}$, orthorhombic, space group $P 2{ }_{1} 2_{1} 2_{1}, \mathrm{~T}=291$ (2) $\mathrm{K}, a=11.009$ (3) $\AA, b=12.679$ (3) $\AA, c=$ 32.617 (10) $\AA, V=4553$ (2) $\AA^{3}, D c=1.04 \mathrm{Mg} / \mathrm{m}^{3}, \mathrm{Z}=8, F_{(000)}=1568, \mu_{(\mathrm{Mo}-\mathrm{K \alpha})}=0.063 \mathrm{~mm}^{-1}$. A total of 27598 reflections $(-11 \leq h \leq 10,-12 \leq k \leq 13,-34 \leq l \leq 28)$, were collected in the range of $1.72^{\circ}<\theta$ $<22.09^{\circ}$, with 3183 independent reflections [R (int) $=0.061$ ], completeness to $\theta$ max was $99.1 \%$. The structure was refined by full-matrix least-square on $F^{2}$, with a final discrepancy index $R$ of 0.0417 based on 2128 observed reflections $[I>2 \sigma(I)]$ and 479 variable parameters. The overall $R \mathrm{w}$ value was 0.0747 with $w=1 /\left[\sigma^{2}\left(F_{\mathrm{o}}{ }^{2}\right)+(0.0265 P)^{2}+0.2811 P\right]$ where $P=\left(F_{\mathrm{o}}{ }^{2}+2 F_{\mathrm{c}}{ }^{2}\right) / 3$; goodness-of-fit $=1.140$; $(\Delta / \sigma)_{\max }<0.0001$. No residual electron density was outside the range -0.094 to 0.085 e $\AA^{-3}$. The anomalous dispersion effect is small and no reliable evidence of the absolute configuration could be obtained, indeed the final Flack parameter $=0.3$ (14), using 2295 Friedel opposite reflections, is not significant.

All the crystallographic data have been deposited with the Cambridge Crystallographic Data Centre (Accession No. CCDC 650071). Copies of the data can be obtained, free of charge, on application to the Director, CCDC, 12 Union Road, Cambridge CB2 1EZ, UK (fax: +44-(0)1223-336033 or e-mail: deposit@ccdc.cam.ac.uk).

\section{Acknowledgements}

We thank the INTERREG III - ALCOTRA, project N.074 “SALVIA” for financial support. The Xray experiments were performed at the 'Centro di Metodologie Chimico-Fisiche' of University Federico II of Naples, using the equipment of the 'Centro Regionale di Competenza Nuove Tecnologie per le Attività Produttive’ of Campania Region. 


\section{References and Notes}

1. Penso, G. Index Plantarum Medicinalium Totius Mundi Eorumque Synonymorum; O.E.M.F.: Milano, 1983; pp. 845-848.

2. Tomás-Barberán, F.A.; Wollenweber, E. Flavonoid aglycones from the leaf surfaces of some Labiatae species. Plant Syst. Evol. 1990, 173, 109-118.

3. Rodríguez-Hahn, L.; Esquivel, B.; Cárdenas, J. Clerodane Diterpenes in Labiatae. In Progress in the Chemistry of Organic Natural Products; Zechmeister, L., Ed.; Springer: Heidelberg, 1994; Vol. 63, 162 and literature cited therein.

4. Cuvelier, M.E.; Richard, H.; Berset, C. Antioxidative Activity and Phenolic Composition of PilotPlant and Commercial Extracts of Sage and Rosemary. J. Am. Oil Chem. Soc. 1996, 73, 645-652.

5. Romussi, G.; Ciarallo, G.; Bisio, A.; Fontana, N.; De Simone, F.; De Tommasi, N.; Mascolo, N.; Pinto, L. A new diterpenoid with antispasmodic activity from Salvia cinnabarina. Planta Med. 2001, 67, 153-155.

6. Capasso, R.; Izzo, A.A.; Romussi, G.; Capasso, F.; De Tommasi, N.; Bisio, A.; Mascolo, N. A diterpenoid from Salvia cinnabarina inhibits rat urinary bladder contractility in vitro. Planta Med. 2004, 70, 185-188.

7. Capasso, R.; Izzo, A.A.; Capasso, F.; Romussi, G.; Bisio, A.; Mascolo, N. A diterpenoid from Salvia cinnabarina inhibits mouse intestinal motility in vivo. Planta Med. 2004, 70, 375-377.

8. Capasso, R.; Avello, G.; Ascione, V.; D’Alessio, A.; De Fusco, R.; Romussi, G. et al. Antimicrobial activity of a secoisopimarane diterpenoid isolated from Salvia cinnabarina. Proceedings 3rd International Symposium on Natural Drugs; Naples, 2003; pp. 193-197.

9. Alfieri, A.; Maione, F.; Bisio, A.; Romussi, G.; Mascolo, N.; Cicala, C. Effect of a diterpenoid from Salvia cinnabarina on arterial blood pressure in rats. Phytother Res. 2007, 21, 690-692.

10. Duisenberg, A.J.M. Indexing in single-crystal diffractometry with an obstinate list of reflections. J. Appl. Cryst. 1992, 25, 92-96.

11. Hooft, R.W.W. COLLECT; Nonius BV: Delft, The Netherlands, 1999.

12. Sheldrick, G.M. SADABS. Version 2.10; University of Göttingen: Göttingen, Germany, 2003.

13. Altomare, A.; Burla, M.C.; Cavalli, M.; Cascarano, G.L.; Giacovazzo, C.; Gagliardi, A.; Moliterni, A.G.G.; Polidori, G.; Spagna, R. SIR97: a new tool for crystal structure determination and refinement. J. Appl. Cryst. 1999, 32, 115-119.

14. Sheldrick, G.M. SHELXL-97; University of Göttingen: Göttingen, Germany, 1997.

15. Farrugia, L.J. ORTEP-3 for Windows - a version of ORTEP-III with a Graphical User Interface (GUI). J. Appl. Cryst. 1997, 30, 565.

16. Kato, T.; Kabuto, C.; Sasaki, N.; Tsunagawa, M.; Aizawa, H.; Fujita, K.; Kato, Y.; Kitahara, Y.; Takahashi, N. Momilactones, growth inhibitors from rice, Oryza sativa. Tetrahedron Lett. 1973, 39, 3861-3864.

17. Lipson, V.V.; Desenko, S.M.; Orlov, V.D.; Shishkin, O.V.; Shirobokova, M.G.; Chernenko, V.N.; Zinov'eva, L.I. Cyclocondensation of 3-amino-1,2,4-triazoles with esters of substituted cinnamic acids and aromatic unsaturated ketones. Chem. Heterocycl. Comp. 2000, 36, 1329-1335. 
18. Khusainova, N.G.; Mostovaya, O.A.; Azancheev, N.M.; Litvinov, I.A.; Krivolapov, D.B.; Cherkasov, R.A. Reaction of 2-acetyl-5-methyl-2H-1,2,3-diazaphosphole with butane-2,3-diol. Mendeleev Commun. 2004, 5, 212-214.

19. Atta-Ur-Rahman; Akhtar, M.N.; Choudhary, M.I.; Tsuda, Y.; Yasin, A.; Sener, B.; Parvez, M. New diterpene isopimara-7,15-dien-19-oic acid and its prolyl endopeptidase inhibitory activity. Nat. Prod. Res. 2005, 19, 13-22.

20. Cremer, D.; Pople, J.A. General definition of ring puckering coordinates. J. Am. Chem. Soc. 1975, 97, 1354-1358.

Sample Availability: Samples of the compounds $\mathbf{1}$ - $\mathbf{4}$ are available from authors.

(c) 2007 by MDPI (http://www.mdpi.org). Reproduction is permitted for noncommercial purposes. 